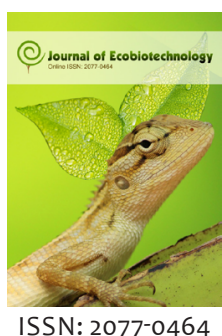

ISSN: $2077-0464$

Received: August 13, 2020 Revised: October 31, 2020 Accepted: November 07, 2020 Published: November 10, 2020

*Corresponding Author:

Michael Clovis,

Email: miclove83@gmail.com

\section{Assessment of heavy metals in Hibiscus sabdariffa calyces and Moringa oleifera leaves collected from different areas in Tanzania}

\author{
Michael Clovis $^{1^{*}}$, Francis Machumi', Ester Innocent ${ }^{2}$ \\ 'Department of Natural Products Development and Formulations, Institute of Traditional Medicine, Muhimbili \\ University of Health and Allied Sciences, Po Box 65001 Dar es Salaam, Tanzania
}

\begin{abstract}
Medicinal plants are known in prevention and curing of diseases. Contamination of medicinal plants by heavy metals is one of the factors affecting quality of medicinal products from medicinal plants. Heavy metals may enter the edible and medicinal plants through contaminated environment such as water bodies, air or soil. Hibiscus sabdariffa calyces and Moringa oleifera leaves are used in Tanzania as nutritional and disease-remedial herbal drinks. This study assessed heavy metal contamination of Hibiscus sabdariffa calyces and Moringa oleifera leaves collected from Dodoma region (Vikonje, Msanga, Nzuguni A and Nzuguni B village), Pwani region (Kongowe and Chalinze village) and Shinyanga region (Mwime village).Lead, arsenic, chromium, cadmium and mercury were analyzed by Atomic Absorption Spectrometry. Microsoft excel 2010 software were used to analyze the means of heavy metal concentrations. Levels of chromium in the calyces and leaves of H. sabdariffa and M. oleifera ranged between 0.029-0.221 ppm and 0.019-0.088 ppm respectively while Arsenic was 0.096-0.204 ppm and 0.096-0.219 ppm, respectively. Mercury and Lead were found only in leaves of M. oleifera, mercury was between $0.017 \mathrm{ppm}$ and $0.042 \mathrm{ppm}$ and lead was $0.056 \mathrm{ppm}$. Cadmium was not detected in all plant materials. The concentrations of heavy metals in the selected samples were statistically significant at $(\mathrm{P}<0.05)$. M. oleifera leaves and H. sabdariffa calyces, collected from different regions, had the low levels of heavy metals than recommended limits provided by the Tanzania Medicine and Medical Devices Authority (TMDA) and WHO.
\end{abstract}

KEYWORDS: Hibiscus sabdariffa, Moringa oleifera, heavy metals, Vikonje, Nzuguni A, Nzuguni B, Msanga, Mwime, Kongowe and Chalinze

\section{INTRODUCTION}

The term "heavy metals" refers to natural metallic elements with a density greater than $5 \mathrm{~g} / \mathrm{cm}^{3}$ [1]. Heavy metals are naturally occurring components of the earth's crust that are, neither created nor destroyed, but are simply redistributed [2]. Heavy metals have adverse effects on human health and there-fore heavy metal contamination in food chain deserves special attention. The most problematic heavy metals are $\mathrm{Hg}, \mathrm{Cd}$, $\mathrm{Pb}, \mathrm{As}, \mathrm{Cu}, \mathrm{Zn}, \mathrm{Sn}$, and $\mathrm{Cr}$ [3], [4]. Out of these, $\mathrm{Hg}, \mathrm{Cd}, \mathrm{Pb}$, and $\mathrm{As}$ are non-essential while $\mathrm{Cu}$ and $\mathrm{Zn}$ are essential heavy metals (trace elements). Heavy metals enter the environment through industrial wastes including paper, textile, electroplating and tannery industries and human activities such as mining, wedding, automobile emission, use of pesticides, fertilizers and fungicides containing heavy metals in agriculture activities and natural source such as heavy metal emission from volcanic eruptions, sea-salt sprays, forest fires, rock weathering, biogenic sources and wind-borne soil particles [5], [6]. Heavy metal contaminants in medicinal plants may cause several health problems to consumers including anemia, damage in vital organs like liver, lung, heart and kidney, reproductive and the nervous system problems [1].

World Health Organization (WHO) estimates nearly 70-80\% of the world population still primarily relies on non-conventional medications, mostly derived from herbal plants. WHO has issued Guidelines for the Quality Assessment of Herbal Medicines (WHO, 1993), [7] that shows the importance of quality and safety assessment of medicinal plants and their products for wellbeing of expected users.

The genus Moringa belongs to family Moringaceae and contains thirteen species that are indigenous to Arabia, Africa and Asia [8]. Moringa oleifera Lam is a medicinal plant with great values due to their potential and medicinal applications 
in Tanzania and the world in general. M. oleifera possesses an impressive range of medicinal uses and high nutritional value (Rockwood et al, 2013) [9]. Hibiscus is a genus of more than 200 annual and perennial species native to the subtropical and tropical regions of the world. Hibiscus sabdariffa L. commonly known as Roselle is an herbaceous plant that belongs to the family Malvaceae [10]. In Tanzania, H. sabdariffa is cultivated mainly in the central and coastal regions such as Dodoma and Pwani Region [11]-[13]. H. sabdariffa and M. oleifera have great values in the community for being used as traditional medicine for remedy of cancer, constipation, teeth and gum diseases, impotence, fatigue, malaria, typhoid fever, hypertension and diabetes [14] and they contain high amount of vitamin C, vitamins $A$ and calcium, thus considered as nutritional food. H. sabdariffa and M. oleifera are used in forms of raw materials as vegetable, herbal tea, juice, syrups, flavoring and coloring agent [14]-[16].

Due to health hazards caused by these toxic metals, WHO advocates that herbs and herbal products should not be used without qualitative and quantitative analysis of their heavy metal contents [17]. The present study was carried out to assess the heavy metals contaminants in $H$. sabdariffa calyces and M. oleifera leaves collected from different regions in Tanzania in order to create awareness to cultivators of $H$. sabdariffa and M. oleifera about possible medicinal plant contaminations, especial heavy metals and provide data of safety levels of those metals in the investigated regions, as the main growing areas in Tanzania.

\section{MATERIALS AND METHODS}

\section{Study Design}

The study was experimental where by H. sabdariffa calyces and M. oleifera leaves were analyzed for heavy metals contamination using Atomic Absorption spectrometer (AAS).

\section{Collection of Samples}

In this study the calyces of $H$. sabdariffa and leaves M. oleifera were collected from medicinal plant farms in Mwime village at Kahama district of Shinyanga region, Kongowe and Chalinze village at Kibaha and Bagamoyo district respectively of Pwani region, Msanga village at Chamwino district and Nzuguni A, Nzuguni B and Vikonje village at Dodoma urban district of Dodoma region [Figure 1]. The dry plant materials were packed in white polythene bags, labeled and transported to the Institute of Traditional Medicine of the Muhimbili University of Health and Allied Sciences (ITM-MUHAS), Dar es Salaam. The samples were air dried for one week to remove moisture.

\section{Chemicals and Equipment}

\section{Chemicals}

Analytical grade chemicals and reagents (Nebrix limited, Tanzania): Helium gas, standard stock solutions of As, Pb, Cd, $\mathrm{Hg}$, and $\mathrm{Cr}$, sulfuric acid $\left(\mathrm{H}_{2} \mathrm{SO}_{4}\right)$, potassium permanganate solution $\left(\mathrm{KMnO}_{4}\right)$, potassium per sulfate solution, acetylene gas, nitrous gas and argon gas (TOL, Tanzania), sodium chloridehydroxyl ammonium chloride ( $\mathrm{NH}_{2} \mathrm{OH} . \mathrm{HCl}$ ), hydroxylamine sulfate and stannous chloride, standard reference material.

\section{Equipment}

Atomic Absorption spectrometer (iCE 3000 SERIES AA Spectrometer, Thermo Scientific, Waltham, USA), fumes chamber/hood (Airflow monitor 100, England), VP 100 Vapor System (VP100, Thermo Scientific, China), electronic balance (ATX224-Shimadzu, Kyoto-Japan), mortar and pestle, laboratory test sieve (Endecotts LTD, London. England), beaker, volumetric flask, conical flasks, water bath, funnel, measuring cylinder and micro pipette.

\section{Sample Preparation}

The air dried samples were ground into fine particles and sieved using $212 \mu \mathrm{m}$ mesh at the Government Chemist Laboratory Agency (GCLA), Dar es Salaam. Powdered samples were stored in air tight container for experimental study.

\section{Determination of Heavy Metals}

The heavy metals in powdered samples were determined at the Government Chemist Laboratory Agency (GCLA), Mwanza.

\section{Determination of lead, arsenic, cadmium and chromium}

Powdered plant materials ( $1 \mathrm{~g}$ each) were transferred into $100 \mathrm{ml}$ beaker each. $40 \mathrm{ml}$ of Aquaregia $\left(3: 1 \mathrm{HCl}, \mathrm{HNO}_{3}\right)$ followed by few ant-bumping were added to each beaker and the mixture was heated on the hot plate with $105^{\circ} \mathrm{C}$ for $1 \mathrm{hr}$ and left to near dryness $(5 \mathrm{ml})$, removed and cooled. The digest was filtered by Whatman No 541 into $100 \mathrm{ml}$ volumetric flask and then diluted with $0.1 \%$ Nitric acid up to the mark. Each plant sample was digested and analyzed in duplicate to confirm precision of the result. The blank solution was prepared by taking a mixture of $30 \mathrm{ml} \mathrm{HCl}$ and $10 \mathrm{ml}$ $\mathrm{HNO}_{3}$ and treating similarly as that of the sample.

Standard solutions with different concentrations of 1, 2, 3, 4, 6 ppm were prepared from 50ppm stock solutions for each metal. The Atomic Absorption spectrometer (AAS) was switched on and the required Acetylene gas turned on; for $\mathrm{Pb}, \mathrm{Cd}$ and $\mathrm{Cr}$ while for As, Acetylene and nitrous gas was used. Metal specific lamp was inserted and AAS machine stabilized for 15 Minutes. Standards were analyzed to prepare calibration curves followed with blank and samples analysis in AAS.

\section{Determination of mercury}

Powdered plant materials (lg each) was mixed with $5 \mathrm{ml}$ $\mathrm{H}_{2} \mathrm{SO}_{4}, 2.5 \mathrm{ml}$ conc. $\mathrm{HNO}_{3}$ and $100 \mathrm{ml}$ distilled water in a $250 \mathrm{ml}$ conical flask and $20 \mathrm{ml} 5 \% \mathrm{KMnO} 4$ solution was added then solution was shaken until the purple color was persistent for at least 15 minutes. $8 \mathrm{ml}$ of $5 \% \mathrm{~K}_{2} \mathrm{~S}_{2} \mathrm{O}_{8}$ solution was added, mixed thoroughly and, heated for two (2) hours in a water bath 


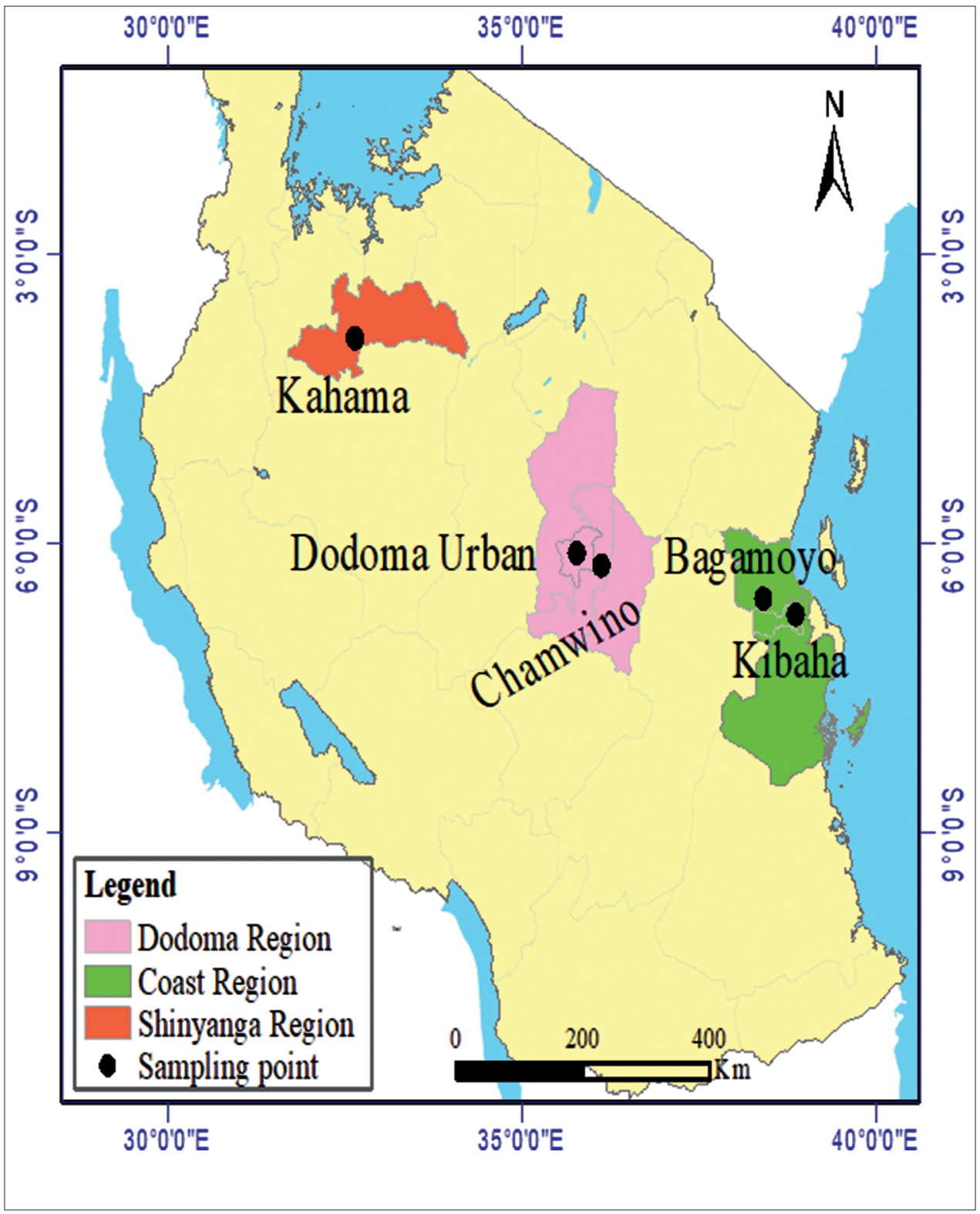

Figure 1: Map of Tanzania to show the location of study areas. Shapefiles source https://www.National Bureau of Statistics.go.tz/index.php/en/ census-surveys/population-and-housing-census/173-2012-phc-shapefiles-level-three

at $85^{\circ} \mathrm{C}$. The solution was cooled at room temperature. $8 \mathrm{ml}$ of $\mathrm{NaCl}-\left(\mathrm{NH}_{2} \mathrm{OH}\right)_{2} \bullet \mathrm{H}_{2} \mathrm{SO}_{4}$ solution was added to reduce the excess permanganate.

Standard solutions with different concentrations of $0.8,1.6,3.2$, $6.4 \mathrm{ppb}$ were prepared from $50 \mathrm{ppm}$ stock solution of mercury. Acid blank reagent $(50 \% \mathrm{~V}$ / or $6 \mathrm{M} \mathrm{HCl})$ and reductant reagent (stannous chloride) were used to increase sensitivity of AAS to mercury [18]. Mercury analysis in standards, blank and samples was performed by VP 100 Cold Vapor Atomic Absorption Spectrometry with detection limit of $0.0001 \mu \mathrm{g} / \mathrm{L}$ (ppb).

\section{Statistical Analysis}

The means of heavy metal concentrations in each plant materials, were analyzed using Microsoft excel 2010 software.
Data were considered statistically differences at significance level $\mathrm{p} \leq 0.05$ and expressed in mean $\pm \mathrm{SD}$.

\section{RESULT}

The means of heavy metals concentrations in each plant materials, were analyzed using Microsoft excel 2010 software as used by Atinafu et al., 2015; Malum and Salihu, 2017 [19], [20]. The results were presented in mean concentration levels and standard deviations of each heavy metal $(\mathrm{Pb}, \mathrm{Hg}$, As, $\mathrm{Cd}$ and $\mathrm{Cr})$ in the plant part material concerned as presented in the tables as follows: Table 3.1 shows the concentration of heavy metals in H. sabdariffa calyces. The mean range concentration levels were between 0.029 to $0.221 \mathrm{ppm}$. The highest concentration of chromium $(0.221 \mathrm{ppm})$ was detected in H. sabdariffa calyces from 
Nzuguni B and lowest (0.029ppm) from Msanga, arsenic (0.204ppm) from Vikonje and $0.096 \mathrm{ppm}$ from Msanga, mercury $(0.038 \mathrm{ppm})$ from Kongowe. Lead and cadmium were not detected. Mean concentrations of heavy metals detected in H. sabdariffa calyces were statistically different $(\mathrm{p}<0.05)$ and were below the recommended limit set by WHO and TMDA in medicinal plants [17], [21].

Table 3.2 shows the concentration of heavy metals ( $\mathrm{Pb}, \mathrm{Hg}$, As, Cd and $\mathrm{Cr}$ ) in $\mathrm{M}$. oleifera leaves. The mean range concentration levels were between 0.017 to $0.219 \mathrm{ppm}$. The highest concentration of chromium $(0.088 \mathrm{ppm})$ was detected in the leaves of $M$. oleifera from Chalinze and Nzuguni B and lowest (0.019ppm) from Msanga, arsenic (0.219ppm) from Nzuguni A and $0.096 \mathrm{ppm}$ from Chalinze, mercury $(0.042 \mathrm{ppm})$ from Nzuguni B and $0.017 \mathrm{ppm}$ from Nzuguni A and Lead (0.056ppm) from Nzuguni B. Cadmium was not detected. Mean concentrations of heavy metals detected in $M$. oleifera leaves were statistically different $(\mathrm{p}<0.05)$ and were below the recommended limit set by WHO and TMDA in medicinal plants [17], [21].

\section{DISCUSSION}

The levels of heavy metals in medicinal plant samples collected from Kongowe, Nzuguni A, Vikonje and Msanga were found to contain relatively higher amount of arsenic than that of Chalinze, and Nzuguni B, while those collected from Mwime had no arsenic. The higher concentration of arsenic might be

Table 3.1: The amount of heavy metals in $H$. sabdariffa calyces

\begin{tabular}{lccccc}
\hline Areas & \multicolumn{5}{c}{ Heavy metals concentration (ppm or mg/Kg) } \\
\cline { 2 - 6 } & $\mathrm{Pb}$ & $\mathrm{As}$ & $\mathrm{Cr}$ & $\mathrm{Cd}$ & $\mathrm{Hg}$ \\
\hline Nzuguni A & $\mathrm{N} / \mathrm{D}$ & $0.191 \pm 0.002$ & $0.033 \pm 0.013$ & $\mathrm{~N} / \mathrm{D}$ & $\mathrm{N} / \mathrm{D}$ \\
Nzuguni B & $\mathrm{N} / \mathrm{D}$ & $\mathrm{N} / \mathrm{D}$ & $0.221 \pm 0.008$ & $\mathrm{~N} / \mathrm{D}$ & $\mathrm{N} / \mathrm{D}$ \\
Msanga & $\mathrm{N} / \mathrm{D}$ & $0.096 \pm 0.004$ & $0.029 \pm 0.012$ & $\mathrm{~N} / \mathrm{D}$ & $\mathrm{N} / \mathrm{D}$ \\
Vikonje & $\mathrm{N} / \mathrm{D}$ & $0.204 \pm 0.007$ & $0.064 \pm 0.003$ & $\mathrm{~N} / \mathrm{D}$ & $\mathrm{N} / \mathrm{D}$ \\
Mwime & $\mathrm{N} / \mathrm{D}$ & $\mathrm{N} / \mathrm{D}$ & $\mathrm{N} / \mathrm{D}$ & $\mathrm{N} / \mathrm{D}$ & $\mathrm{N} / \mathrm{D}$ \\
Kongowe & $\mathrm{N} / \mathrm{D}$ & $0.169 \pm 0.002$ & $\mathrm{~N} / \mathrm{D}$ & $\mathrm{N} / \mathrm{D}$ & $0.038 \pm 0.001$ \\
P-Value & - & $6.2 \times 10^{-9}$ & $1.56 \times 10^{-5}$ & - & $2 \times 10^{-9}$ \\
TMDA limits & 10 & 1 & 2 & 0.3 & 0.5 \\
WHO limits & 10 & 1 & 2 & 0.3 & 0.1 \\
\hline
\end{tabular}

Abbreviation: N/D- Not detected, PPM-Part per million or $\mathrm{mg} / \mathrm{kg}$, TMDA- Tanzania Medicine and Medical Devices Authority, WHO- World Health Organization caused by contaminations from animal manure and pesticides applied to other crops such as millets and sun flower plants that were found cultivated together with medicinal plants in the same farm. The study by [5], [22], [23] found that, application of pesticides and manure in agriculture is the source of arsenic, lead and mercury in soil and crops. Arsenic causes cancer, damage to the skin, eyes and liver and affect kidneys and central nervous system [24], [25].

Chromium was detected in all medicinal plant samples except calyces sampled from Mwime and Kongowe. Cigarette smokes and sewage sources might be the main sources of chromium contamination [1], this is due to the reason that, most of medicinal plant farms are surrounded with residence areas. Chromium may results to cancer, drowsiness, fatigue, hair loss, insomnia, memory loss, recurrent infections, restlessness, vision disturbances [24].

Trace amount of mercury was found in M. oleifera and H. sabdariffa from Nzuguni A, Nzuguni B and Kongowe respectively and lead detected only in $M$. oleifera from Nzuguni B. The trace amounts of mercury and lead might be originated from pesticides applied to mixed crops and paints used for home decoration [5], [22], [23]. Exposure to lead is cumulative over time, high concentrations of lead in the body can cause cardiovascular disease and to children causes impaired development, reduced intelligence, loss of short- term memory, learning disabilities, coordination problems and finally death or permanent damage to the central nervous system, brain, and kidneys [22], [26], [27]. Short time exposure to mercury can cause lung damage, kidney damage and affect nervous system [25].

Cadmium was not detected in all medicinal plants; this could mean that there is low pollution with respect to cadmium in the study areas.

Generally, the detected heavy metals might be originated from human activities such as application of pesticides and animal manures in crops, painting, cigarette smokes and sewage disposal or natural sources such as rock weathering and wind-borne soil particles.

Table 3.2: The amount of heavy metals in M. oleifera leaves

\begin{tabular}{|c|c|c|c|c|c|}
\hline \multirow[t]{2}{*}{ Areas } & \multicolumn{5}{|c|}{ Heavy metals concentration (ppm or mg/Kg) } \\
\hline & $\mathrm{Pb}$ & As & $\mathrm{Cr}$ & $\mathrm{Cd}$ & $\mathrm{Hg}$ \\
\hline Nzuguni A & $N / D$ & $0.219 \pm 0.002$ & $0.045 \pm 0.007$ & $\mathrm{~N} / \mathrm{D}$ & $0.017 \pm 0.003$ \\
\hline Nzuguni B & $0.056 \pm 0.003$ & $0.120 \pm 0.008$ & $0.088 \pm 0.009$ & $\mathrm{~N} / \mathrm{D}$ & $0.042 \pm 0.002$ \\
\hline Msanga & $\mathrm{N} / \mathrm{D}$ & $0.210 \pm 0.005$ & $0.019 \pm 0.004$ & $\mathrm{~N} / \mathrm{D}$ & $\mathrm{N} / \mathrm{D}$ \\
\hline Mwime & $\mathrm{N} / \mathrm{D}$ & $\mathrm{N} / \mathrm{D}$ & $0.050 \pm 0.007$ & $\mathrm{~N} / \mathrm{D}$ & $N / D$ \\
\hline Kongowe & $\mathrm{N} / \mathrm{D}$ & $0.212 \pm 0.004$ & $0.039 \pm 0.004$ & $\mathrm{~N} / \mathrm{D}$ & $N / D$ \\
\hline Chalinze & N/D & $0.096 \pm 0.002$ & $0.088 \pm 0.006$ & $\mathrm{~N} / \mathrm{D}$ & N/D \\
\hline P-Value & $1.81 \times 10^{-8}$ & $9.2 \times 10^{-7}$ & $2.04 \times 10^{-4}$ & - & $2.31 \times 10^{-5}$ \\
\hline TMDA limits & 10 & 1 & 2 & 0.3 & 0.5 \\
\hline WHO limits & 10 & 1 & 2 & 0.3 & 0.1 \\
\hline
\end{tabular}

Abbreviation: N/D- Not detected, PPM-Part per million or mg/kg, TMDA- Tanzania Medicine and Medical Devices Authority, WHO- World Health Organization 


\section{CONCLUSION}

The plant materials of M. oleifera leaves and H. sabdariffa calyces, collected from different regions, had the low levels of heavy metals than recommended limits provided by TMDA and WHO. Even though the plant materials had low levels of heavy metals, it is further recommended to carry out other safety assessments for these plant materials from the studied sites to ensure safety of consumers.

\section{CONFLICTS OF INTEREST}

No competing interests exist.

\section{ACKNOWLEDGEMENT}

Completion of this work was not possible without contributions and support from Government Chemist Laboratory Agency (GCLA) of Dar es Salaam and Mwanza for providing of research facilities and laboratory space, Germany Academic Exchange Service (DAAD) for the fund support and Institute of Traditional Medicines at The Muhimbili University of Health and Allied Sciences.

\section{REFFERENCES}

1 L. Järup, "Hazards of heavy metal contamination," Br. Med. Bull., vol. 68, pp. 167-182, 2003, doi: 10.1093/bmb/ldg032.

2 D. E. Keil, J. Berger-Ritchie, and G. A. McMillin, "Testing for Toxic Elements: A Focus on Arsenic, Cadmium, Lead, and Mercury," Lab. Med., vol. 42, no. 12, pp. 735-742, 2011, doi: 10.1309/ Imykgu05bepe7iaw.

3 S. Ghosh, International Journal of Environmental Sciences, vol. 1, no. 4. West Bengal, India: Integrated Pub. Association, 2010.

4 R. T. Wright, Environmental Science: Toward a Sustainable Future, 9th ed. Jones \& Bartlett, 2007.

5 V. Masindi and K. L. Muedi, "Environmental Contamination by Heavy Metals," Heavy Met., 2018, doi: 10.5772/intechopen.76082.

6 D. Paul, "Research on heavy metal pollution of river Ganga: A review," Ann. Agrar. Sci., vol. 15, no. 2, pp. 278-286, 2017, doi: 10.1016/j. aasci.2017.04.001.

7 WHO, IUCN, and WWF, Guidelines on the Conservation of Medicinal Plants. 1993

8 M.. Olson, "Combining Data from DNA Sequences and Morphology for a Phylogeny of Moringaceae (Brassicales)," SystematicBotany, vol. 27, pp. 55-75, 2002, Accessed: Feb. 28, 2019. Online. Available: https://www.jstor.org/stable/pdf/3093895.pdf.

9 J.. Rockwood, B.. Anderson, and D. Casamatta, "Potential uses of moringa oleifera and an examination of antibiotic efficacy conferred by $M$. oleifera seed and leaf extracts using crude extraction techniques available to underserved indigenous populations," Int. J. PHYTOTHEARPY Res., vol. 3, no. 2, pp. 61-71, 2013.

10 A. Diessana, C. Parkouda, M. Cissé, B. Diawara, and M. H. Dicko, "Optimization of Aqueous Extraction of Anthocyanins from Hibiscus sabdariffa L. Calyces for Food Application," Food Sci. Qual. Manag., vol. 45, pp. 2224-6088, 2015, Online. Available: www.iiste.org.

11 M. J. Moshi et al., "Promotion of Community based Commercial Cultivation of Herbal Medicines and Packaging of Herbal
Nutritional Supplements.," 2007. Accessed: Mar. 01, 2019 Online. Available: http://dspace.muhas.ac.tz:8080/xmlui/bitstream/ handle/123456789/63/Final First year Rockefeller2Report. pdf? sequence $=1$ \&isAllowed $=y$.

12 E. Peter, K. O. Mashoto, S. F. Rumisha, H. M. Malebo, A. Shija, and N. Oriyo, "Iron and Ascorbic Acid Content in Hibiscus sabdariffa Calyces in Tanzania: Modeling and Optimization of Extraction Conditions," Int. J. Food Sci. Nutr. Eng., vol. 4, no. 2, pp. 27-35, 2014, doi: 10.5923/j.

13 Z. H. Mbwambo et al., "Promotion of Community based cultivation of Hibiscus sabdariffa, Moringa oleifera, Adansonia digitata and Aloe vera for use as herbal nutritional supplements for people living with HIV/AIDS Final Report," 2007. Accessed: Mar. 04, 2019. Online. Available: http://dspace.muhas.ac.tz:8080/ xmlui/bitstream/handle/123456789/64/Mbwambo2007 etal. pdf? sequence $=1$ \&isAllowed $=\mathrm{y}$.

14 A. Leone, A. Spada, A. Battezzati, A. Schiraldi, J. Aristil, and S. Bertoli, "Cultivation, Genetic, Ethnopharmacology, Phytochemistry and Pharmacology of Moringa oleifera Leaves: An Overview.," Int. J. Mol. Sci., vol. 16, no. 6, pp. 12791-835, Jun. 2015, doi: 10.3390/ ijms160612791.

15 A. K. M. A. Islam, T. S. Jamini, A. K. M. M. Islam, and S. Yeasmin, "Roselle: A Functional Food with High Nutritional and Medicinal Values," Fundam. Appl. Agric., vol. 1, no. 2, pp. 44-49, 2016, Accessed: Feb. 26, 2019. Online. Available: http://www.f2ffoundation. org/faa/wp-content/uploads/sites/2/2016/08/1.-FAA-2016-012.pdf.

16 V. Suresh, "Medicinal uses of Roselle (Hibiscus sabdariffa)," J. Med. Plants Stud., vol. 5, no. 4, pp. 97-98, 2017, Accessed: Feb. 26, 2019. Online. Available: http://www. plantsjournal.com/archives/2017/ vol5issue4/PartB/5-4-10-840.pdf.

$17 \mathrm{WHO}$, "WHO guidelines for assessing quality of herbal medicines with reference to contaminants and residues," World Heal. Organ. p. 118, 2007, doi: ISBN 9789241594448.

18 P. Dominski and D. E. Shrader, "Automated Cold Vapor Determination of Mercury : EPA Stannous Chloride Methodology," pp. 1-8, 1984.

19 T. Atinafu, I. Vol, I. Oct, T. Mekonnen, and J. Somasundaram, "Determination of some toxic heavy metal accumulation in medicinal plants commonly used in Gondar area district, Northwestern Ethiopia," vol. 4, no. 4, pp. 399-405, 2015.

20 Y. M. Malum and L. Salihu, "Determination of Heavy Metals in Hibiscus cannabinus and Moringa oleifera Cultivated at Zango Abattoir , Tudun Wada, Kaduna Metropolis," vol. 3, no. 4, pp. 32-35, 2017, doi: 10.11648/j.ijsdr.20170304.11.

21 Tanzania Food and Drugs Authority, "Tanzania Food and Drug Authority Guidelines for Application for Registration of Traditional Medicina Products," 2014. Accessed: Mar. 04, 2019. Online. Available: www. tfda.or.tz,.

22 R. A. Wuana and F. E. Okieimen, "Heavy metals in contaminated soils: A review of sources, chemistry, risks, and best available strategies for remediation," Heavy Met. Contam. Water Soil Anal. Assessment Remediat. Strateg., vol. 2011, p. 20, 2011, doi: 10.1201/b16566.

23 P. Thangavel and C. Subbhuraam, "Phytoextraction: role of hyperaccumulators in metal contaminated soils," Proc. Indian Natl. Sci. Acad. Part B, Biol. Sci., vol. 70, no. 1, pp. 109-130, 2004, Accessed: Mar. 02, 2019. Online. Available: https://www. researchgate.net/publication/284396760_Phytoextraction_Role_of Hyperaccumulators in Metal Contaminated Soils.

24 K. Gulati, B. Banerjee, S. B. Lall, and A. Ray, "Effects of diesel exhaust, heavy metals and pesticides on various organ systems: possible mechanisms and strategies for prevention and treatment.," Indian J. Exp. Biol., vol. 48, no. 7, pp. 710-21, Jul. 2010.

25 O. A. Abosede, "Review on heavy metals contamination in the environment," Eur. J. Earth Environ., vol. 4, no. 1, 2017.

26 H. Salem, E. Eweida, and A. Farag, "Heavy metals in drinking water and their environmental impact on human health," Cairo, 2000

27 L. N. Kolonel, "Association of Cadmium with renal cancer," Cancer Res., no. 37, pp. 1782-1787, 1976. 